\title{
Inbreeding and outbreeding impact on developmental stability of laboratory rat Rattus norvegicus
}

\author{
Vyacheslav I. BORISOV, Alexey V. VALETSKY, Irina L. DMITRIEVA, \\ Natalia L. KRUSHINSKAYA and Vladimir M. ZAKHAROV
}

\begin{abstract}
Borisov V. I., Valetsky A. V., Dmitrieva I. L., Krushinskaya N. L. and Zakharov V. M. 1997. Inbreeding and outbreeding impact on developmental stability of laboratory rat Rattus norvegicus. [In: Developmental homeostasis in natural populations of mammals: phenetic approach. V. M. Zakharov and A. V. Yablokov, eds]. Acta Theriologica, Suppl. 4: $67-72$.

Developmental stability analysis was conducted for three strains of laboratory rat Rattus norvegicus Berkenhout, 1769 and their hybrids. Developmental stability was estimated by fluctuating asymmetry of 20 characters of skull morphology. A decrease was revealed in fluctuating asymmetry for the inbred strains and for the hybrids of genetically different strains. There were not any differences in fluctuating asymmetry between the homo- and heterozygotes for the separate locus. This support the hypothesis of the dependence of developmental stability on general genetic coadaptation.

N. K. Koltzov Institute of Developmental Biology, Russian Academy of Sciences, Vavilov Str. 26, Moscow 117808, Russia

Key words: Rattus norvegicus, fluctuating asymmetry, developmental stability, heterozygosity, inbreeding, genetic coadaptation
\end{abstract}

\section{Introduction}

Developmental stability was established as an important population parameter, ie measure of environmental stress (Soulé 1967, Zakharov 1987, 1992). From the genetic point of view all data obtained suggest that the level of developmental stability assessed even for a single phenotypic character mainly depends on overall characteristics of the genome: average level of heterozygosity or general genetic coadaptation have been assumed as the main factors affecting developmental stability level (Zakharov and Bakulina 1984, Ferguson 1986, Leamy 1986, Zakharov 1987, Graham 1992, Clarke 1994). Developmental stability decrease with heterozygosity decline have been registered in numerous studies (Soulé 1979, Leary et al. 1983, Mitton 1994, 1995), but in some others the contradictory results have been revealed (Wooten and Smith 1986, Graham 1992, Fowler and Whitlock 1994). More data of the simultaneous study of developmental stability for the 
homo- and heterozygotes for the separate loci as well as for the inbreeding and outbreeding impact are needed to verify the hypotheses.

The aim of this study is to assess the developmental stability of rat Rattus norvegicus Berkenhout, 1769 under inbreeding and outbreeding impact and to interpret the results in the light of the hypotheses of its dependence on the heterozygosity and on the general genetic coadaptation.

\section{Material and methods}

Three strains of laboratory rats were used for the study. Two of them ("Bright" and "Dull") derived from the two pairs each from the well-known R. Tryon's strains: "maze-bright" and "maze-dull" respectively, established according their ability for extrapolation distinguished in the test in the complex labyrinth (Wahlsten 1972). The third strain "KD" was established from 6 pairs collected from the wild strain derived from the natural population in Moscow region through 10 generations of selection for the high extrapolation ability distinguished in the test with the moving food (Sokolov et al. 1977).

The samples from each of these three strains ("Bright", "Dull" and "KD") were studied. The sample (that was conditionally called as "KD1") collected from the strain "KD" after 4 years of the laboratory maintenance was also analyzed. Hybrids of reciprocal crosses of closely related British strains ("Bright" and "Dull") as well as hybrids between genetically different strains (British strain "Bright", males, and Russian strain "KD1", females) were used for the study (Table 1).

Vertical polyacrylamide gel electrophoresis was employed by Maurer (1968): tris-glycine buffer for electrodes, $\mathrm{pH}=8.3$; tris-phosphate, $\mathrm{pH}=6.9$ - for concentrating gel, and tris-chloride, $\mathrm{pH}=8.9$ for distinguishing gel, to appreciate genetic heterogeneity. Staining recipes for enzymes were adapted from Serov et al. (1977). General proteins were stained with amido-black $10 \mathrm{~B}$, transferrins were identified using their ability to dissolve in rivanole (Tikhonov and Zharkova 1973). There were resolved 11 enzyme systems and 3 non-enzymatic proteins, encoded by 19 presumptive gene loci: aspartate aminotransferase (AAT, E.C. 2.6.1.1, Aat-1, Aat-2), glycerol-3-phosphate dehydrogenase

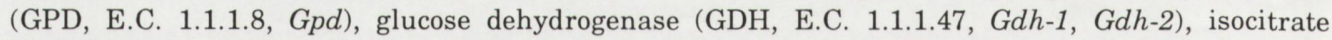
dehydrogenase (IDH, E.C. 1.1.1.42, Idh), lactate dehydrogenase (LDH, E.C. 1.1.1.27, Ldh-1, Ldh-2), malate dehydrogenase (MDH, E.C. 1.1.1.37, $M d h$ ), malic enzyme (ME, E.C. 1.1.1.40, $M e$ ), peroxydase (PXD, E.C. 1.11.1.7, Pxd-1, Pxd-2, Pxd-3), 6-phosphogluconate dehydrogenase (PGD, E.C. 1.1.1.44, $P g d$ ), superoxide dismutase (SOD, E.C. 1.15.1.1, $\mathrm{Sod}$ ), xanthine dehydrogenase (XDH, E.C. 1.2.3.2, $X d h$ ), albumin (ALB, Alb), prealbumin (PALB, Palb), transferrin (TRF, Trf), and number of the loci coding for multiple hemoglobin and muscle proteins.

Developmental stability was estimated by fluctuating asymmetry, small non-directional differences between the sides of the body (Van Valen 1962, Zakharov 1987). Twenty non-metric characters as a number of foramina at different skull bones were used for the study. The characters are described and defined in Fig. 1 in Valetsky et al. 1997. No significant indications for the directional asymmetry or antisymmetry were registered for (l-r) distribution of these characters (Van Valen 1962, Palmer and Strobeck 1986). All characters and their asymmetries were not correlated with each other. As there was no difference for the parameter values between males and females the summarized samples of both sexes were analyzed.

Fluctuating asymmetry was estimated by the integrated index - mean number of asymmetrical characters per individual (Leary et al. 1983, 1985, Zakharov 1987, 1989). Student's $t$-statistic was used to estimate the significance of intergroup difference in this parameter (Sokal and Rohlf 1981). 


\section{Results}

Developmental stability study of the rat samples consists of the following steps:

(1) Comparison of the three laboratory strains. All three initial strains ("Bright", "Dull" and "KD") have got the similar values of the integrated fluctuating asymmetry index (Table 1).

(2) Comparison of the homo- and heterozygotes for the separate locus. All electrophoretically tested loci controlling several enzyme and non-enzyme proteins proved to be homozygous for the same alleles in all strains under study. There was only one exception in the strain "KD": 15 of 38 tested individuals (39.5\%) within the strain sample were heterozygous for the locus controlling 6-phosphogluconate dehydrogenase. Comparison of the homo- and heterozygous individuals

Table 1. Mean number of asymmetrical characters (NA $\pm \mathrm{SE}$, of 20 characters of skull morphology, Fig. 1 in Valetsky et al. 1997) in the various samples of the laboratory rat Rattus norvegicus. $n$-sample size.

\begin{tabular}{lcr}
\hline Sample & $n$ & NA \pm SE \\
\hline Strain "Dull" & 42 & $8.881 \pm 0.336$ \\
Strain "Bright" & 40 & $9.075 \pm 0.340$ \\
Strain "KD" (total) & 39 & $8.513 \pm 0.448$ \\
$\quad$ 6-Pgd heterozygotes & 14 & $8.214 \pm 0.720$ \\
$\quad$ 6-Pgd homozygotes & 25 & $8.680 \pm 0.579$ \\
Strain "KD1" & 37 & $11.243 \pm 0.330$ \\
Hybrids "Dull" × "Bright" (total) & 32 & $7.194 \pm 0.345$ \\
$\quad$ Hybrids "Dull" × "Bright" & 12 & $8.083 \pm 0.416$ \\
$\quad$ Hybrids "Bright" $\times$ "Dull" & 20 & $7.100 \pm 0.446$ \\
Hybrids "KD1" × "Bright" & 7 & $5.000 \pm 0.617$ \\
\hline
\end{tabular}

for the marker locus $(P g d)$ within the strain "KD" has not revealed any differences between them in the level of fluctuating asymmetry (Table 1).

(3) Study of the laboratory maintenance impact. Only 2 of 41 tested individuals (4.9\%) proved to be still heterozygous for the locus Pgd after 4 years of the laboratory maintaining of the strain "KD" (ie in "KD1" sample). Fluctuating asymmetry was significantly higher $(p<0.001)$ in "KD1" sample than in the sample from the initial strain "KD" (Table 1).

(4) Study of the closely related strains hybridization impact. Hybrids between two closely related strains ("Dull" and "Bright") were characterized by essentially lower fluctuating asymmetry value than the initial strains $(p<0.01)$ (Table 1$)$.

(5) Study of the genetically different strains hybridization impact. Hybrids between genetically different strains ("Bright" and "KD1") were characterized by significantly higher $(p<0.001)$ fluctuating asymmetry level than the original strains (Table 1). 


\section{Discussion}

In the highlight of the discussion on the genetic background of developmental stability our data could be interpreted as follows. Comparing homo- and heterozygous specimens for a single locus it was not possible to reveal any differences. This support the hypothesis that a transition of a separate locus from the heterozygous to the homozygous state will not necessarily lead to essential change in an organisms condition in general and in developmental stability in particular. Superiority of heterozygote in developmental stability assumes the overdominant effect when the heterozygous state of the certain locus is determining the essential improvement of an organism condition that could not be expected for any loci. Thus, the effect has been revealed only for a few of numerous analyzed loci in rainbow trout (Leary et al. 1983). In such cases an advantage effect of heretozygosity was manifested not only for developmental stability, but also for an overall organism condition, including rate of growth, etc (Ferguson 1986). Positive correlation of developmental stability with the growth rate was also established for roach (Ruban and Zakharov 1984).

Deterioration of developmental stability as a result of long-term inbreeding indicates a negative effect of the increase in average homozygosity level. In this case developmental stability decrease is a manifestation of inbreeding depression. Homozygosity for the alleles with deleterious effect as well as an increased sensitivity of homozygotes could be the main causes for the developmental stability disturbance under the impact of inbreeding. High developmental stability of the inbred strain of Drosophila melanogaster under optimal environmental conditions (Astauroff 1930) and high fitness of the homozygous silk worm Bombix mori clones established through the special selection to eliminate the alleles with a deteriorative effect (Strunnikov 1994) serve the needed background for the latter explanation.

We have obtained different results in our cross experiments. Crossing of closely related inbred strains resulted in an increase in developmental stability. A transition of the loci from the homozygous to the heterozygous state, including the alleles with deleterious effect, could be the main cause of the effect. Possible negative effect of genetic coadaptation decrease should be less that an advantage of the removing of the inbred depression. Vice versa, crossing genetically different strains deterioration of developmental stability took place as a result of the combination of incompatible alleles, that led to genetic coadaptation disruption. Possible positive effect of the removing of the inbreeding depression is much less than deleterious effect of the genetic coadaptation disruption. These data correspond to the earlier obtained results of the inter and intrapopulation crosses (Tebb and Thoday 1954, Zakharov and Bakulina 1984).

Summarizing all our data we can conclude that: (1) homo- or heterozygous state of the single locus does not commonly affect developmental stability; (2) an increase in genomic homozygosity leads to developmental stability decrease (inbreeding depression); (3) an increase of heterozygosity results in developmental stability 
increase when we cross closely related inbred strains (removing of inbreeding depression) and in developmental stability decrease when we cross essentially different strains (genetic coadaptation disruption). Thus, developmental stability could be suggested as a general characteristic of an organism condition, as one of the fitness parameters. The level of developmental stability mainly depends not on heterozygosity as such, but on overall genomic characteristic, genetic coadaptation, that could be disrupted under the certain circumstances by both inbreeding or outbreeding.

Acknowledgements: We are very grateful to two anonymous referees provided very helpful comments and corrections of English.

\section{References}

Astauroff B. L. 1930. Analyze der erblichen Storungsfalle der bilateralen Symmetrie im Zusammenhang mit der selbstständigen Variabilität änlicher Strukturen. Zeitschrift für inductive Abstammungs und Vererbungslehre 55: 183-262.

Clarke G. M. 1994. The genetic basis of developmental stability. I. Relationships between stability, heterozygosity and genomic coadaptation. [In: Developmental instability: its origins and evolutionary implications. T. A. Markow, ed]. Kluwer Academic Publishers, London: 17-25.

Ferguson M. M. 1986. Developmental stability of rainbow trout hybrids: genomic coadaptation or heterozygosity? Evolution 40: 323-330.

Fowler K. and Witlock M. C. 1994. Fluctuating asymmetry does not increase with moderate inbreeding in Drosophila melanogaster. Heredity 73: 373-376.

Graham J. H. 1992. Genomic coadaptation and developmental stability in hybrid zones. Acta Zoologica Fennica 191: 121-131.

Leamy L. 1986. Directional selection and developmental stability: evidence from fluctuating asymmetry of dental characters in mice. Heredity $57: 381-388$.

Leary R. F., Allendorf F. W. and Knudsen K. L. 1983. Developmental stability and enzyme heterozygosity in rainbow trout. Nature 301: 71-72.

Maurer H. R. 1968. Disc-Electrophorese. Theorie und Praxis der diskontinuierlichen Polyacrylamidgel -Elektro-phorese. Walter de Gruyter und Co, Berlin: 1-247.

Mitton J. B. 1994. Enzyme heterozygosity, metabolism and developmental stability. [In: Developmental instability: its origins and evolutionary implications, T. A. Markow, ed]. Kluwer Academic Publishers, London: 49-68.

Mitton J. B. 1995. Enzyme heterozygosity and developmental stability. Acta Theriologica 40, Supplement 3: 33-54.

Palmer R. A. and Strobeck C. 1986. Fluctuating asymmetry: measurement, analysis, patterns. Annual Review in Ecology and Systematic 17: 391-421.

Ruban G. I. and Zakharov V. M. 1984. [Comparison of rapid- and slow-growing forms of the roach (Rutilus rutilus) according to developmental stability.] Doklady Akademii Nauk SSSR 277: 1510-1512. [In Russian]

Serov O. L., Korochkin L. I. and Manchenko G. P. 1977. [Electrophoretical methods for enzymes research.] [In: Genetics of allozymes. D. K. Belaev, ed]. Nauka, Moskva: 18-64. [In Russian]

Sokal R. R. and Rohlf F. J. 1981. Biometry. Freeman, San-Francisco: 1-859.

Sokolov V. E., Lyapunova K. L. and Khorlina I. M. 1977. [Behavioral peculiarities and social structure formation in the groups of Norway rats (Rattus norvegicus norvegicus Berkenhout, 1769) under laboratory conditions.] [In: Povedenie mlekopitayushikh. V. E. Sokolov, ed]. Nauka, Moskva: 84-106. [In Russian] 
Soulé M. E. 1967. Phenetics of natural populations. II. Asymmetry and evolution in a lizard. Ammerica Naturalist 101: 141-160.

Soulé M. E. 1979. Heterozygosity and developmental stability: another look. Evolution 33: 3963-401.

Strunnikov V. A. 1994. [The nature of heterosis and new methods of its increase.] Nauka, Moskva 1-108. [In Russian]

Tebb G. and Thoday J. M. 1954. Stability in development and relational balance of X-chromosoomes i: Drosophila melanogaster. Nature 174: 1109-1110.

Tikhonov V. P. and Zharkova S. F. 1973. [Polyacrilamide electrophoresis of serum fractionns wit] rivanol.] Laboratornoye Delo 6: 357-360. [In Russian]

Valetsky A. V., Dmitrieva I. L., Krushinskaya N. L. and Zakharov V. M. 1997. Social stress imppact o developmental stability of laboratory rat Rattus norvegicus. [In: Developmental homeosttasis i: natural populations of mammals: phenetic approach. V. M. Zakharov and A. V. Yablokovv, eds] Acta Theriologica, Suppl. 4: 27-32

Van Valen L. 1962. A study of fluctuating asymmetry. Evolution 16: 125-142.

Wahlsten D. 1972. Genetic experiments with animal learning: a critical review. Behavioral bioology 7 143-183.

Wooten M. C. and Smith M. H. 1986. Fluctuating asymmetry and genetic variability in matura population of Mus musculus. Journal of Mammalogy 67: 725-732.

Zakharov V. M. 1987. [Animal asymmetry: population-phenogenetic approach.] Nauka, Moskva 1-231. [In Russian]

Zakharov V. M. 1989. Future prospects for population phenogenetics. Soviet Science Reviews, iSectiol F 4 (3): 1-79.

Zakharov V. M. 1992. Population phenogenetics: Analysis of developmental stability in matura populations. Acta Zoologica Fennica 191: 7-30.

Zakharov V. M. and Bakulina E. D. 1984. Disturbance of developmental stability at crossing diifferen strains of Drosophila virilis (variation in the number of ovarioles taken as an example). Grenetik: 20: 1390-1391. [In Russian with English summary]

Received 7 December 1995, revised 10 October 1996, accepted 15 April 1997. 